\title{
Is There A Place For Us? Social Workers of Color As Outside Agitators Within the Profession
}

\author{
Michael Rangel
}

\begin{abstract}
The outside agitator narrative has been used to discredit and harm people of color for decades. Currently, it is being used as a forceful tactic to separate the movement for Black lives from the broader narrative that racism is deeply rooted in American social structures, institutions, and everyday life. This article examines the implications of how the profession of social work has similarly and simultaneously maintained a culture of white supremacy and racist ideologies in our work. As outsiders in a predominantly white profession, social workers of color act as outside agitators when dispelling myths and practices used in and for communities of color. By centering the lived experiences and knowledge of social workers of color, all social workers can increase their awareness of racism within our profession and work together to dismantle the culture of racism and white supremacy that persists within social work.
\end{abstract}

Keywords: Social workers of color, outside agitator, social work profession

Outside agitators have historically been represented as unfamiliar forces enacting violence and unruliness in spaces where injustice occurs. From the civil rights era to this moment in history for Black lives, outside agitator narratives and depictions have intently, yet simultaneously blamed and ignored the progression of a movement. In the context of social work as a profession, the representation of an outside agitator narrative has been used to displace and erase social workers of color from being represented and heard in a profession that is predominantly white. According to "Profile of the Social Work Workforce" report by the Council on Social Work Education, $68.6 \%$ of social workers identify as white, $21.6 \%$ as Black/African American and other racial and ethnic groups with percentages below four percent (Salsberg et al., 2017). In recent years, due to an increase in what I consider a more visible and tangible white supremacy that has been further institutionalized by racist government leaders, it has become normal for social workers of color to be perceived as unruly and overly-critical of the profession at large because of our larger relationship with the state and these institutions. Simultaneously, social workers of color are unruly for advocating for their communities and participating in protests, campaigns, and scholarship that promotes racial justice. For actual outsiders of the profession, social work seems to be at the forefront of social change; but what is actually happening is a dismissal of a much more rooted and deeper racial and systemic inequity and injustice plagued by policing, hyper-incarceration, human caging, and death (Jacobs et al., 2021). I conceptualize systems interchangeably, both as institutions and structural agencies, but also as the systems we tend to use in social work of the individual, family, community and society which influences our interpretation throughout this paper of the systems we may agitate. Within the profession of social work, people of color have continuously contested the very nuances and complexities of social work as it is today. By

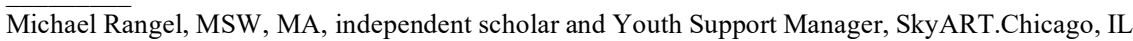


continuing to teach and practice predominantly white ideologies and practices, the entire profession continues to replicate existing systems of oppression.

In this conceptual paper, I use historical analysis and critical race theory to consider the problems that happen as social workers of color live and practice within the profession with an outsider perspective and social positioning. Over the last century, the profession has grown accustomed to accepting western and white understandings of social work. There is a fundamental need for a critical cultural competency and dialogue of practices rooted in the liberation for people of color, but where is it in social work? The myth is that social workers cannot challenge and critique the very practices we learn and teach. Casting social workers of color as instigators of dissent when challenging the profession of social work as a whole has consequently obscured the myriad of instances in which social work does not challenge its complicity and complacency in white supremacy. This paper will work through the archival reconstruction and reimagine social work's possibilities for social workers of color as being their own agents of change and knowledge producers. First, I provide a brief contemporary framing of this issue and its connection to the political and public discourses happening both within and outside of the profession. Second, through archival reconstruction, I expand possibilities for social work with a genealogical tracing of the outside agitator narrative in the civil rights era to that of todays fight for Black Lives. Working through this history, I expand theorization of "Outsider" narratives and posit a reimagination of possibilities for social workers of color. And finally, centering social workers of color, specifically Black and Brown social workers, in the profession of social work as leading experts in work that affects our communities, our livelihood, and ourselves. Deconstruction of dominant narratives and building powerful narratives challenges our epistemological processing of what it means to be a social worker, what is the social work profession's intentions and impact, and how can we all, in this moment and through this movement, dismantle white supremacy and racism in our society and in our profession.

Through social work, white supremacy is embedded in processes that diagnose, treat, analyze and theorize about people of color's experiences and trauma, but then do nothing to change social work's involvement in it. It reflects how our profession's broader affinity for blaming its internal divisions on the work of external adversaries has created dissections. This is a call to action for all social workers to work towards the re-imagination of a world without white supremacy while working towards the liberation for all people of color at its core.

In writing this I am enraged, and devastated, and grieving. I am agitated. I am angry. We will not and should not accept that the lives of marginalized people are disposable to the state that perpetuates doctrines and laws that facilitate racism, displacement, and an ultimate corporeal and social death. Social work was originally intended to participate in the welfare of people within the limits set by these existing values of white supremacy and racism. Now more than ever, it is imperative we engage in the work of changing our society, starting with the basic values of our society and disinvesting in oppressive political, cultural and social systems. Amongst the scenes of police guarding buildings and capital of the state, there is a clear choice of whom this country wants to see alive. Living in hope 
and catastrophe, the collective process and work needed in our profession is dependent on our ability to work towards a future together.

\section{We Agitated}

In the summer of 2020, the uprising for Black lives perpetuated a reaction and narrative that undermines the impact "justice" and social work has had on our democracy. President Trump's authoritarian and militarized response and push for escalated police presence enacted a summer of violence onto not only American streets, but international response. This parallels with the ongoing debate between social workers and the National Association of Social Workers' response calling for more police presence in social work spaces and practices, such as the opinion piece in the Wall Street Journal by National Association of Social Workers chief executive officer Angelo McClain (McClain, 2020). All the while, news outlets and the media have characterized protestors and community organizers as depersonalized and dehumanized criminals and agitators. These narratives have historically and internationally been used to discredit insurgent movement building and protests against injustices happening all around us. From Tunisia's Jasmine Revolution, Minneapolis and Ferguson, to Egypt's Arab Springs - civil resistance continues to challenge state powers (Busby, 2020). And specifically the practice of civil resistance in these critical moments emphasizes that there is neither law, nor order.

In response to a ploy to label outside agitators as harmful and violent people to the movement, it is necessary that we re-convene and re-construct our understanding of the term and recognize the grievances and expressions of people being affected by the institution or issue in question. The outside agitator narrative and its history across time exemplify the multifaceted ways in which white supremacy and racism have coerced institutions into blaming outsiders, erroneously claiming agitations as a behavior of nonmembers of the institution. Specifically for Balfour and colleagues (2020) in Unmasking Administrative Evil, they point to the ways in which there is a private versus public phenomenon that occurs when naming who is for and or against the institution. In this case, people of color have historically been pitted as inherently "bad" to counter the actual oppression that whiteness produces and sustains. The agitator response and narrative has been widely used in the aftermath of police violence unrest, specifically in the cases of Trayvon Martin, Michael Brown, Freddie Gray, and now; Breonna Taylor, George Floyd and Elijah McClain (Muwakkil, 2020). The outside agitator trope has been used for a long time in the United States to reinforce the unruly tradition of American racism and white supremacy. Now in the Trump era, modern day segregationists who support draconian, militarized, panic and response to civil uprisings are using this same tool of "distraction and division" (Freire, 1968/2018, p. 141). This label has historically and is contemporarily used to bend towards a system of escalated violence rather than towards justice and allows powerful and privileged people, such as the American president of 2020, to avoid acceptance of the reality a deeply racist system has created from then to now.

There is no "outsider" for communities of color, for they are inside the totality of systemic oppression in the U.S. (Chowdhury, 2014). The U.S. government is aware of the violence, the anger, the death and the continual disregard for marginalized people, 
specifically in this movement for Black Life. Perhaps the resurgence of the "outside" narrative is necessary to government officials at a time like this where justice for Black people is an injustice to the legacy of white supremacy that is critical towards the legacy of the United States of America. Can justice only occur if it is for and by the insider? But then, who is declared and presumably on the inside? With recent actions and exchanges by the government, there is a clear decision for who technically in our society is on the inside. The insidiousness of outsider narratives in the summer of 2020, amongst the stresses of the presidential election and the heightened presence of whiteness, was an over- and recriminalization of Black people as "looters" and the glorification of white protesters and white social workers wanting to "help" as innocent bystanders (an example we will re-visit as it pertains to social workers) - a narrative of white saviorism and white vigilantism we are all too familiar with when glimpsing into the past from Ferguson to Sanford to Katrina.

To be an outsider instigates the idea that there is no place for those who live within the margins to be on the "inside." The outsider is usually a person or group of people who hold oppositional ideologies and practices that differ greatly from the insiders. As an outsider, there is usually only one way to access the inside, and that is to conform, adjust, and assimilate to the actions and behaviors of the insiders. The social work profession has long used this practice to regulate and control the lives of women of color through the welfare state, through responses to gender violence, and state violence (Kim, 2018).

It can be noted and observed that there is an under-reporting and un-reporting of writings from within the profession of social workers who are aware of the injustices that occur in the profession of social work as a whole. In writing this paper, it is clear that our grievances and agitations go much unwritten and unannounced, but not unnoticed. It seems fitting that these stories and experiences occur together, in intimate and closed settings. But, in this particular time in history against white supremacy and racism, it is imperative more narratives from social workers of color are told, written, and taught. Though we witness extreme stories of state violence and injustices, the less reported and coded way of being an agitator plays a major role in this outsider rhetoric as well by exemplifying the tactics to restrict coverage, mobilization, policy change, and actual transformative justice. Even in the profession, through journals and articles on cultural sensitivity, diversity and inclusion, and race related topics, much of the rhetoric is created by and for white social workers to be digestible and comfortable conversations.

In assigning characteristics and behaviors to agitator narratives, the larger deployment of violence disproportionately affects communities of color, primarily Black and Brown communities. The reliance on a fixed system with the inability for Black and Brown people to grieve or express their feelings, shifts the focus to the protection and prioritization of white anger and power. The problem with the outside agitators is two-fold. One, it perpetuates echoes of the agitator as being "outside" of the affected group or group in question. This perpetuates the idea that those "locals" on the inside are not inclined to disagreement or opposition. Second, it causes concerns that there is a political or extraneous agenda that comes along with the outsiders that is foreign and not contingent on the ideologies of the "insiders." Both of these problems with this trope then justifies violent resistance by the "insiders" to change, and historically have been used to repeatedly marginalize real opposition and ignore systemic racism (Zhou, 2020). Wouldn't this cause 
you to be agitated too? However, in no way does an agitation for the system mean that you should be placed on the outside. But, social workers of color are accustomed to acting and performing within the margins--this narrative is not new, but it is contingent on the ethics and profession of social work to acknowledge and change that.

\section{Echoes of the Agitator}

In 1964, the governor of Alabama, George Wallace said, "We have never had a problem in the South except in a few very isolated instances and these have been the result of outside agitators" (The Gilder Lehrman Collection, n.d., para. 4). This was a response to the civil rights movement happening throughout the South. The perpetual use of the outsider agitator rhetoric in issues pertaining to racial justice allowed the government and court officials to cast suspicion on the actual legitimacy, saliency, and scope of racial justice (Bloom, 2020; Collins, 2020; Eidman-Aadahl, 2020). Images of heavily armed white police forces confronting and attacking Black and Brown protesters have transcended time and space, from this current moment to that of the civil rights era to the rebellions occurring during slavery. Though technologies, institutions, and governmentality have changed, the echoes of the agitator persist.

The distinction being made between outsiders and the people occupying space and participating in civil resistance has precedent in a long history of race relations in this country. Ferguson and Minneapolis are certainly not Selma, Tulsa, Birmingham, or Little Rock, but even those who are familiar with the rhetoric and public discourse can acknowledge the unruly comparisons and striking similarities of the outside agitator narratives. I am not going to provide numbers of arrest that exemplify that outsiders are not from the inside because how do you measure grief or exhaustion or death, or in this specific case Black grief or Black death? Here I stop and think about Christina Sharpe's (2016) book, In the Wake, and how she navigates Black temporalities, care, flesh, performance, and movement. Sharpe's work is critical here because it tells us how Black resistance of non/being has been used to impose grief, loss, memory, and death onto those outside of any possibility for protections or citizenship or visibility by the state. Regardless of who was arrested in this time, who "looted", and who challenged the state - our focus should be on the historical lineage of the outside agitator myth and just how prevailing it has traveled time.

The outside agitator narrative can be traced back to instances of Black rebellion in US histories and the commonwealth's justification for enslavement (Bloom, 2020). Specifically, the example of the 1811 German Coast Uprising which was the largest slave revolt in US history that made Governor Claiborne of the Territory of New Orleans control the immigration of enslaved and free Black people from the Caribbean because he insisted on outside help to the rebels (Dormon, 1977). Though this could not be proven, it exemplifies one of the earliest instances where behaviors and characteristics of those inside the revolt were undoubtedly cast on outside influences.

During the Reconstruction era, Ida B. Wells, an acclaimed journalist, speaker, and social justice advocate, led an international fight against lynching and protested these murders publicly (Bay, 2009). Wells combated the erosion of Black civil, social, and 
political rights that plagued the Jim Crow south and influenced life for Black people during this time. A leader in the anti-lynching movement, Wells faced many social and cultural challenges, often being placed on the outside of organizations and movements she is credited for starting, largely due to her race and gender (Bay, 2009). Well's life provides invaluable historical testimony to her critical resistance and persistence of an outside agitator narrative that has greatly impacted modern day social work, but most importantly the legacy she left for social workers of color.

In the civil rights era, the outside agitator narrative was perpetually used in the descriptions of leaders who were challenging the racial divide in America. In 1965, protesters in Selma were attacked, beaten, and tear-gassed by the Alabama police for being blamed as outsiders to the city, even though many of those on the bridge that day were residents of the city (Fortin, 2020). Often during the outside agitator narratives of the 1950s and $1960 \mathrm{~s}$, the term was used as a distraction by popular media and the government from civil resistance and demonstrations that demanded justice and lawful basic human rights. These ideas in the civil rights era were a part of the greater racist ideologies that these ideas of basic human rights could not have come from Black people in the South, or that the ideas could even be their own (Fortin, 2020). Similarly, in Ferguson in 2014 and Baltimore in 2015, responders filled the streets to protest the killing of Michael Brown and then Freddie Gray. Commentators and headlines referred to the protestors and those arrested as "outsiders" (Chowdhury, 2014) and from out of state where again, the idea to protest and resist the injustices of racial policing and police killing were outside ideas.

The echoes of the agitator have traveled throughout time and space and do so in a continuum of racial injustice and civil resistance that is the true spirit of America. The history of the outside agitator is long, drawn out, and perpetual, but this is not the last time we will engage in this narrative. Until justice is here, the echoes of the agitator will live on in the resistance and fight for our lives.

\section{Outsider Narratives and Notes From the Margin}

Blatant denial is a powerful tool for the government, elected politicians, and white social workers in leadership. The re-framing of national issues as non-localized shifts responsibility and incentive to act (Turner, 2020). This shift acts as an anchor to delay action and redirect the course of legal responsibility that was initially being challenged. In doing so, government officials and the ruling class blame the violence on the victims. Thus, rather than admittedly calling out the larger institutions and people at fault, the blame is on the members who might hold actual grievances for the harm and violence done. So, calling to those of us/them/we that live in the margins is essential in accessing the knowledge and the teachings from inside the outsiders' experiences.

Much of the workings of social work with social workers of color revolve more around our recruitment and retention than our teachings and education (Castex et al., 2019). With the publishing of Ethnic Minorities in Social Work Education in 1970 authored by Carl A. Scott (1970), the sentiment remains the same to this day, that there is a clear distinction of who choses to be social workers and who is fully accepted into the profession. Many social workers from marginalized backgrounds enter the field with the hope of fighting injustices, 
but are constantly met with instances of bias, stereotypes, discrimination and harm from the profession (Castex et al., 2019).

Other workings noted from the margins that affect our accessibility and ability to be a part of the profession include the consistent and persistent use of cultural competency. In its origins, cultural competency was the means for working with non-white racial, ethnic, and cultural groups and with it came the deficit-oriented depiction of people and communities of color (Abrams \& Moio, 2009). Though fortunate to have texts such as Doman Lum's Social Work Practice and People of Color: A Process Stage Approach (1999) and Culturally Competent Practice: A Framing for Understanding (2003), the need is for an understanding that goes beyond a consensus that marginalized communities and people color suffer and are in need. There is a need for more than self-awareness or skill development, but an accountability and accessibility for social workers of color will be directly impacted by the profession. The dialogue must become clearer that the first step is to not call it "cultural competency," but the work should not and will not stop there. I follow the critiques of social work scholars who have noted the inability of cultural competency to reach far enough for social workers to challenge institutional racism, white supremacy, and oppressions (Abrams \& Moio, 2009). It should lead to a practice and strategy for the clients and community we all so intently work to support. It should be focused around and center justice.

I include this section because it requires a reading of the outside narrative as more than an agitation to the institution or the system, but a reading of the performance and production of the outsider and its necessity to the profession. If in our trainings we were given direction to read foundational texts by Black and Brown scholars such as Angela Y. Davis's Women, Race, and Class (1981) or Are Prisons Obsolete? (2003), fellow social worker Charlene Carruthers (2018) Unapologetic: A Black, Queer, and Feminist Mandate for Radical Movements, or Audre Lorde's (1984) Sister Outsider, we would/will be better equipped as social workers and scholars to interact in the scenes of marginalization that haunt this country. If able to enter spaces with a better framework of the history communities of color have lived and are living through, social workers will be able to critically engage in rhetoric and public discourse surrounding issues of racism, anti-blackness, anti-immigration, and the prison industrial complex that directly and indirectly greatly impacts the lives of social workers of color.

\section{Social Workers of Color in These Streets}

In the portrayal of the outsider and the history of the agitator, there is a specific place for social workers of color in this diaspora. Initially, I think about the reverberation of Jane Adams and other white women as being the core producers and executives to the profession of social work. But, with the framework of Critical Race Theory, we can assess how racism is an ordinary and everyday occurrence for people of color, and in this instance, social workers of color (Abrams \& Moio, 2009). In doing so, we can notice how white created and produced social work excludes racial and minority perspectives and experiences to indirectly justify and legitimize its power in the profession. By using Critical Race Theory, social workers of color can actively tell the alternatives to history and acknowledge the 
intersectionality of their lives that our profession does not include (Abrams \& Moio, 2009). From the National Association of Black Social Workers, to the Asian Pacific Islander Social Work Council, to the Association of Latina/Latino Social Work Educators, the role and influence of social workers of color is astronomical and largely benefits a social work where Critical Race Theory and Ethnic Studies is used to pursue justice and dismantle white supremacy.

Though Critical Race Theory helps social workers notice how racism is embedded into the policies and practices of society, can it do the same in noticing how racism is embedded in our profession? Social Workers of color encounter more than representational policy barriers, but formidable societal, educational, and economic barriers that are present before, during, and after their social work education (Castex et al., 2019). So can a shared professional identity occur in social work if there is a racist structure that impacts social workers of color? Possibly, but it will not look like a social work created by Jane Adams or Mary Richmond. It will carry over ecological and self-identity perspectives and systems theories, and the persons-in-environment approach, but can these dispute white supremacy and not reinvent or rename it? Will this social work hold space for clinical, communal, and comparative social work that can be interdisciplinary and multifaceted? Can our classrooms teach both historical and contemporary epistemologies of social work that has at its praxis the profession, and not resurgent aesthetics of racism and white supremacy?

The outsider agitators' agitation to the systems will perpetually exist as long as there is a ruling class and race of people deciding what is and is not justice. One of the most noted figures in the civil rights era, Martin Luther King Jr. wrote, "Whatever affects one directly, affects all indirectly. Never again can we afford to live with the narrow, provincial 'outside agitator' idea. Anyone who lives inside the United States can never be considered an outsider anywhere within its bounds." (King, 1963, as cited by Eidman-Aadahl, 2020, "So on we go...", para. 2). The claims of an outsider being present in civil resistance, uprisings, and social work fail to recognize the basic realities of the economic and social conditions that exist for communities of color in the US. To be poor and Black in this country is recognizable to the outsiders narrative, that aims to police, violate, and control these bodies reasoned to be left in the margins.

As Kanishka Chowdhury, Professor of English and Director of the Program in American Culture and Difference at the University of St. Thomas discusses it in his article, Outsiders in Ferguson (2014), ordinary people cannot expect those in power, the true outsiders, to solve any problem for the greater good, for the people. In social work, to be an agitator is where resistance and revolution must start and will include insiders and outsiders to the profession. There is no better time than now to consistently and comparatively challenge and critique the systems that sustain violence and white supremacy in our communities and in our profession.

\section{Conclusion}

It is now time to re-read our work, be critical in our formations, and use our imagination for how we can survive in both the inside and outside of social work. Maybe it's not even our words, maybe it's a gesture or embodiment of what it means to be both a person of 
color and a social worker, on top of other identities that complicate and beautify our life. Our insurgent histories and imaginaries conscript our capacity to imagine what is possible in the profession. But what does it mean to search within the outside of our profession? How can we as social workers of color, who code switch on command and navigate predominantly white spaces, use this skill and this tool to do the work both within a system that does not recognize us; and at the margins where we are from? What does this say about social work if the inside is uninhabitable to us? Is it meant for us to live inside at all?

I want this to be a very important ethical and critical tool that comes from us working for and within our communities. Whether in community, in our homes, or in an institutional setting, there needs to be a deeper investigation into how and why social workers of color are not being incorporated into the education and practical training of social workers and why when we do, there is a hesitation and reluctance to our inwardness.

This conceptualization of social workers of color as outside agitators is related to the idea that social work as a profession is sustained and constructed as a place for only white people. I write this as a both/and critique of social work; where both social workers of color and white social workers can engage in critical discourses over the ongoing harm social work as a whole perpetuates onto social workers of color and where white social workers can gain a perspective and a tool that can support them in actively implementing not just academic reform to their practices, classrooms and interventions, but actual social and communal justice. But most importantly, I write this for the social workers of color that are fighting for their safety and their space on a daily basis in a profession that largely rejects our place in it. Once we begin to understand that it is not the past we must reconcile, it is the present, then our work for the future begins.

\section{References}

Abramovitz, M. (2017). Regulating the lives of women: Social welfare policy from colonial times to the present. Routledge. https://doi.org/10.4324/9781315228150

Abrams, L. S., \& Moio, J. A. (2009). Critical race theory and the cultural competence dilemma in social work education. Journal of Social Work Education, 45, 245-261. https://doi.org/10.5175/jswe.2009.200700109

Balfour, D. L., Adams, G. B., \& Nikels, A. E. (2020). Unmasking administrative evil (5th ed.). Taylor and Francis.

Bay, M. (2009). To tell the truth freely: The life of Ida B. Wells. Macmillan.

Bloom, N. (2020, July 6). Blaming "outside agitators" for street protests is not a distraction- it's an American call to arms. IEHS Online. https://www.iehs.org/blaming-outside-agitators-for-street-protests-is-not-adistraction-its-an-american-call-to-arms/\# ftn7

Busby, J. (2020, June 9). Beware the "outside agitator" dog whistle. Duck of Minerva. https://duckofminerva.com/2020/06/beware-the-outside-agitator-dog-whistle.html

Carruthers, C. (2018). Unapologetic: A Black, queer, and feminist mandate for radical movements. Beacon Press. 
Castex, G., Senreich, E., Phillips, N. K., Miller, C. M., \& Mazza, C. (2019). Microaggressions and racial privilege within the social work profession: The social work licensing examinations. Journal of Ethnic \& Cultural Diversity in Social Work, 28(2), 211-228. https://doi.org/10.1080/15313204.2018.1555498

Chowdhury, K. (2014, August 14). Outsiders in Ferguson. Counter Punch. https://www.counterpunch.org/2014/08/21/outsiders-in-ferguson/

Chowdhury, K. (2020, June 1). The return of the "outside agitator". Counter Punch. https://www.counterpunch.org/2020/06/01/the-return-of-the-outside-agitator/

Collins, J. (2020, June 9). The American myths of the 'black wrecker' and 'outside agitator'.Medium. https://medium.com/@j.collins/the-american-myths-of-the-blackwrecker-and-outside-agitator-43b95621ace9

Constance-Huggins, M. (2012). Critical race theory in social work education. Critical Social Work, 13(2), 1-16. https://doi.org/10.22329/csw.v13i2.5861

Davis, A. Y. (1981). Women, race, \& class. Vintage.

Davis, A. Y. (2003). Are prisons obsolete? Seven Stories Press.

Dormon, J. H. (1977). The persistent specter: Slave rebellion in territorial Louisiana. Louisiana History, 18(4), 389-404. https://www.jstor.org/stable/4231728

Eidman-Aadahl, E. (2020) The "outside agitator" trope, asked and answered. Medium. https://elyseea.medium.com/the-outside-agitator-trope-asked-and-answerede $79538 \mathrm{~b} 70 \mathrm{e} 68$

Fortin, J. (2020, June 8). The long history of the 'outside agitator'. The New York Times. https://www.nytimes.com/2020/06/08/us/outside-agitators-history-civil-rights.html

Freire, P. (2018). Pedagogy of the oppressed. Bloomsbury Publishing. (Original work published 1968)

Gilder Lehrman Collection. (n.d.). History resources: George Wallace on segregation, 1964. https://www.gilderlehrman.org/history-resources/spotlight-primarysource/george-wallace-segregation-1964

Jacobs, L. A., Kim, M. E., Whitfield, D. L., Gartner, R. E., Panichelli, M., Kattari, S. K., \& Mountz, S. E. (2021). Defund the police: Moving towards an anti-carceral social work. Journal of Progressive Human Services, 32(1), 37-62. https://doi.org/10.1080/10428232.2020.1852865

Kim, M. E. (2018). From carceral feminism to transformative justice: Women-of-color feminism and alternatives to incarceration. Journal of Ethnic \& Cultural Diversity in Social Work, 27(3), 219-233. https://doi.org/10.1080/15313204.2018.1474827

Lum, D. (1999). Social work practice and people of color: A process-stage approach (4th ed.). Brooks.

Lum, D. (2003). Culturally competent practice: A framework for understanding diverse groups and justice issues. Brooks. 
McClain, A. (2020, June 15). Social workers cooperate with police forces. The Wall Street Journal. https://www.wsj.com/articles/social-workers-cooperate-with-policeforces-11592255480

Salsberg, E., Quigley, L., Mehfoud, N., Acquaviva, K. D., Wyche, K., \& Silwa, S. (2017). Profile of the social work workforce: CSWE Report. https://www.cswe.org/Centers-Initiatives/Initiatives/National-WorkforceInitiative/SW-Workforce-Book-FINAL-11-08-2017.aspx

Scott, C. A. (1970). Ethnic minorities in social work education: A collection of papers highlighting developments and issues concerning faculty, students, and curriculum in social work education. Council on Social Work Education.

Sharpe, C. (2016). In the wake: On blackness and being. Duke University Press. https://www.dukeupress.edu/in-the-wake

Zhou, L. (2020, June 15). The trope of "outside agitators at protests, explained. Vox. https://www.vox.com/2020/6/3/21275720/george-floyd-protests-outside-agitatorsferguson-civil-rights-movement

Author note: Michael Rangel, SkyART, Chicago, IL 60617. Email:

michvrangel@gmail.com 